This item was submitted to Loughborough's Research Repository by the author.

Items in Figshare are protected by copyright, with all rights reserved, unless otherwise indicated.

\title{
Magneto-forming studies
}

PLEASE CITE THE PUBLISHED VERSION

https://doi.org/10.1109/PPC.2017.8291316

PUBLISHER

IEEE

VERSION

AM (Accepted Manuscript)

LICENCE

CC BY-NC-ND 4.0

REPOSITORY RECORD

Alotaibi, Faisal T., Bucur M. Novac, Peter Senior, Ivor R. Smith, Vahid Nekouie, Anish Roy, and Vadim V.

Silberschmidt. 2019. "Magneto-forming Studies". figshare. https://hdl.handle.net/2134/32572. 


\title{
MAGNETO-FORMING STUDIES
}

\author{
T. Alotaibi ${ }^{\xi}$, B. M. Novac, P. Senior, I.R. Smith, V. Nekouie, A. Roy and V. Silberschmidt \\ School of Mechanical, Electrical and Manufacturing Engineering, Loughborough University, \\ Loughborough, Leicestershire LE11 3UE, UK
}

\begin{abstract}
The paper describes preliminary experimental studies of magneto-forming technology, undertaken at Loughborough University and using the existing $2 \mathrm{MA} / 100$ kJ Quattro capacitor bank as power supply. Different practical arrangements will be detailed and results presented that illustrate magneto-forming in thetapinch geometry:

- Magneto-forming stainless steel cylinders

- Welding stainless steel cylinders with stainless steel cylinders.

- Magneto-forming magnesium cylinders.

For each arrangement, the results of magneto-forming are analyzed at the interface as well in the adjoined materials in comparison with their pre-manufacture (as delivered) state. The used characterization techniques include microand nano-indentation, optical microscopy and scanning electron microscopy.
\end{abstract}

\section{INTRODUCTION}

Electromagnetic forming, or magneto-forming, is a method used since the 1950s to reshape, deform or change the shape of electrically conductive materials. A very high current is induced in the work piece due to a high intensity and fast pulsed magnetic field, which in turn causes a high repulsive magnetic field that repels the pulse and by induction causes parts of the work piece to deform in the form required [1].

Research and development in this field has his roots historically in the techniques used to generate a very high magnetic field in the range of Megagauss ( $1 \mathrm{MG}=100 \mathrm{~T}$ ) by implosion. Before the electromagnetic forming method became a mature feasible technology C.M. Fowler et al. [2] reported the generation of Megagauss fields using chemical explosives to implode metallic cylinders (liners). Much later, ultra-high magnetic fields greater than $700 \mathrm{~T}$ were generated indoors, but these experiments unavoidably always result the destruction of the coil due to the very high intensity Maxwell stress. These technologies however allowed the magneto-forming to gain further research interest.

The present project aims to explore the magneto-forming technology, by conducting experiments and building models that will provide accurate predictions for different industrial applications. Industry related applications include magnetic implosions for shaping, welding and coating. Well-known industrial manufacturers provided Loughborough with a list of technical difficulties that the modern industry is facing so that this project can focus on delivering high quality solutions for these issues.

\section{II.GENERALITIES}

The pulsed power system used is extremely simple. A magnetic coil is energized by a capacitor bank $\mathrm{C}$ that generates a main primary current $\mathrm{I}_{\mathrm{P}}$. A secondary current $\mathrm{I}_{\mathrm{S}}$ is produced by induction in the imploding cylinder (liner), mounted inside the magnetic coil and the interaction between the two opposed currents produces a radial force that is responsible for the liner implosion, as shown in Fig. 1. Unique support for this experimental work is provided by a detailed 2-dimensional numerical code. The developed software, only briefly presented here, is capable of predicting the current and temperature distributions in the imploding cylinder and, most importantly, the imploding dynamics, enabling the electromagnetic implosion system to be both accurately designed and controlled.

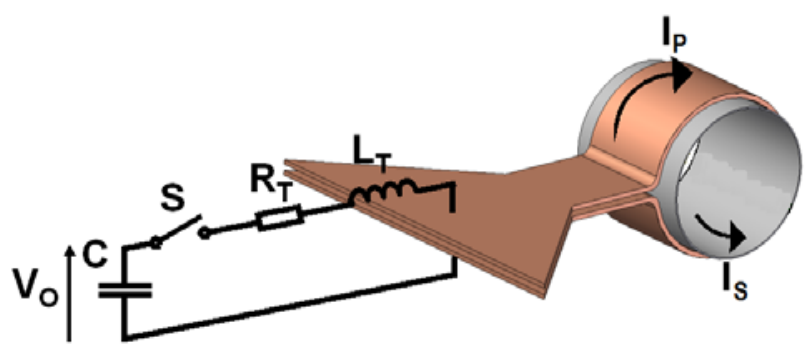

Figure 1. Primary $I_{P}$ and secondary induced current $I_{S}$.

The main aims of the present phase of the Loughborough magneto-forming project are

- To build a mathematical model to predict the current, velocity, temperature and other magnetoforming characteristics

- To use a large capacitor bank to deliver currents exceeding $1 \mathrm{MA}$ while accurately control the parameters which this project aims to achieve.

- To successfully implode and possibly even weld steel, aluminum and magnesium cylinders.

\footnotetext{
६ email: T.Z.M.B.Alotaibi@lboro.ac.uk
} 


\section{EXPERIMENTAL ARRANGEMENT}

\section{A. System equivalent circuit}

The equivalent electric circuit of the system is shown in Fig. 2.

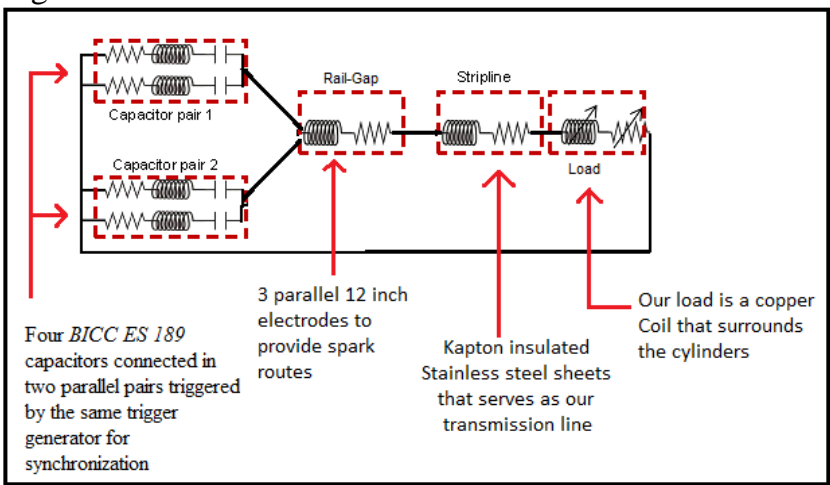

Figure 2. Equivalent electric circuit representation of the system with details of each element.

\section{B. Capacitor bank}

The capacitor bank setup at the Magneto-Forming Facility, presented in Figure, is used for different experimental configurations such as cylindrical implosions and flat plate acceleration.

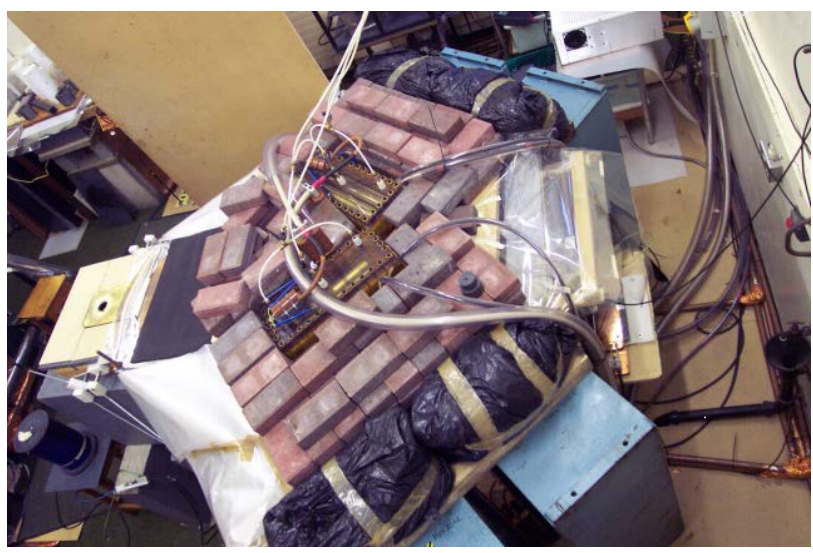

Figure 3. Capacitor bank setup at Loughborough University Magneto-Forming Facility

\section{Rail Gap Switches}

The capacitor bank is triggered using two, parallelmounted, 40302rail gap switches. The two switches are located on top of a polyurethane base. Their two main electrodes are made of brass and the trigger knife edged electrode is mounted in between. While operated, the switch interior is filled with a gas mixture of oxygen and argon and triggered by a $100 \mathrm{kV} / 10 \mathrm{~ns}$ two stage Marx generator as shown in Figure 4.

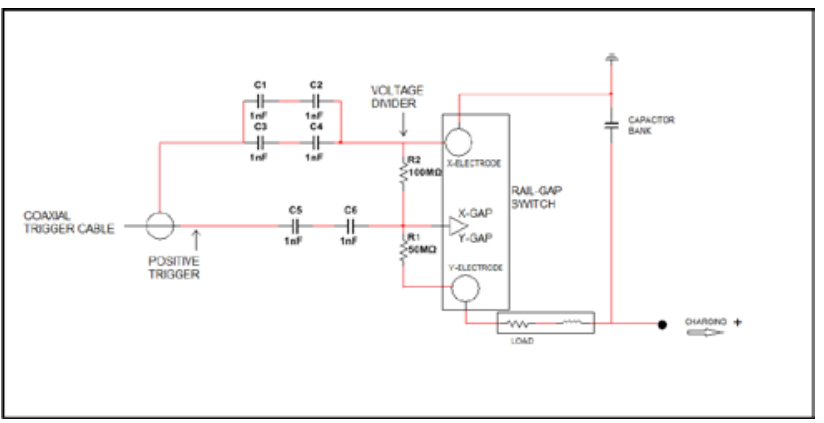

Figure 4. Rail gap switch and its triggering circuit.

\section{Magnetic coil and imploding cylinder (liner)}

For these preliminary experiments, the sacrificial magnetic coil is made simply from copper as shown in Figure 5. Inside the coil, the sample is mounted coaxially, with a thin Mylar sheet between the two elements introduced for electrical insulation.

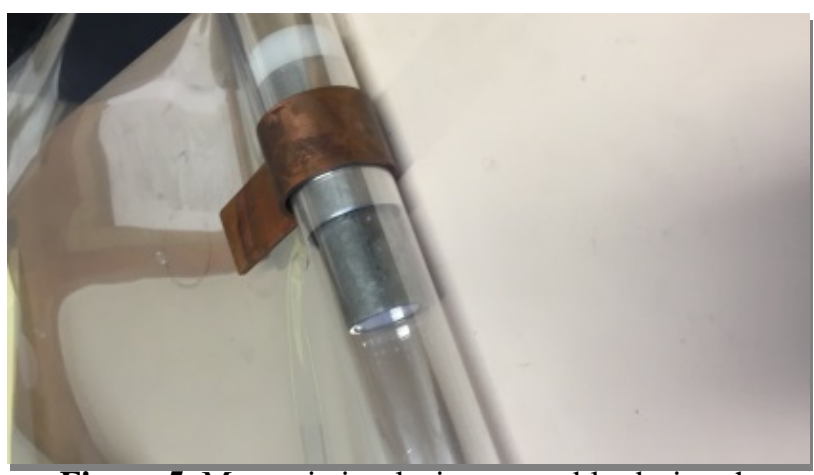

Figure 5. Magnetic implosion assembly during the preparations for a shot. The sacrificial copper coil has the imploding samples for cold welding mounted inside.

\section{ELEMENTS OF NUMERICAL MODELLING}

Figure 6 describes a simplified electric scheme for the system discussed in this report. The 2-D code will only be briefly introduced, with details provided later elsewhere. In reference to Figure 6 once the switch is closed a current begins to flow through the primary circuit and induced current flows in the secondary circuit, in an opposite direction. In such conditions a Maxwell stress is generated which compresses the liner inwards. The basic equations for the two currents and the charge injected by the capacitor into the circuit can be written as: 


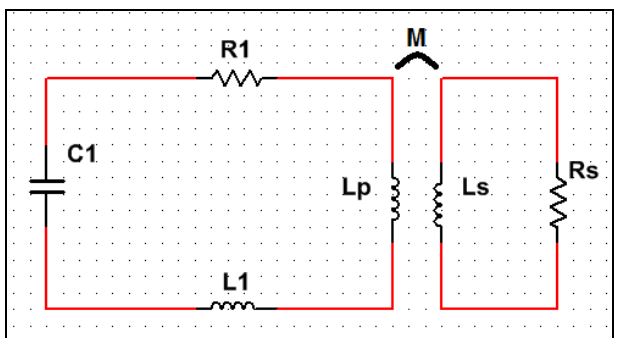

Figure 6. Equivalent circuit of the system.

$V_{0}-\frac{Q}{C 1}=L 1 \frac{d I_{p}}{d t}+R 1 I_{p}+L_{p} \frac{d I_{p}}{d t}+M \frac{d I_{s}}{d t}$

$\frac{d Q}{d t}=I_{p}$

$0=L_{s} \frac{d I_{s}}{d t}+M \frac{d I_{p}}{d t}+R_{s} I_{s}$

The time rate-of-change of the two currents can then be obtained as:

$$
\begin{aligned}
& \frac{d I_{s}}{d t}=\frac{V_{0}-\frac{Q}{C}-R I_{p}-M \frac{d I_{s}}{d t}+\frac{\left(L+L_{p}\right)}{M} . . R_{s} I_{s}}{M-\frac{L_{s}\left(L+L_{p}\right)}{M}} \\
& \left.\frac{d I_{p}}{d t}=-\frac{L_{s}\left[\frac{V_{0}-\frac{Q}{C}-R I_{p}-M \frac{d I_{s}}{d t}+\frac{\left(L+L_{p}\right)}{M} \cdot . R_{s} I_{s}}{M-\frac{L_{s}\left(L+L_{p}\right)}{M}}\right]+R_{s} I_{s}}{M}\right]
\end{aligned}
$$

The equations 2, 4 and 5 can then be integrated to obtain the currents. A sample of the model results is shown in Figure 7, where the experimental current is compared with the current predicted for a test in which a stainless steel cylinder, with an initial radius of $49 \mathrm{~mm}$ and a thickness of $2 \mathrm{~mm}$ was successfully imploded The capacitor bank was charged to an initial voltage of $25 \mathrm{kV}$ with the coil current reaching a peak of 1.2 MA.

Full details on how to compute the velocity, the acceleration and the liner temperature will be provided elsewhere.

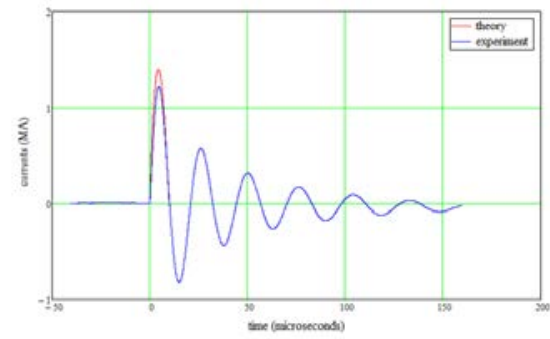

Figure 7. Typical discharge current. Blue trace: experimentally measured and red trace: theoretically predicted.

\section{RESULTS}

\section{A. Magneto-forming imploding tests}

Table I shows details of a few samples tested and Figure 8 the dependence of the final characteristics of steel cylinders upon the initial charging voltage. As expected, a higher charging voltage resulted in a higher imploding percentage. Photos of the magneto-formed samples are also presented in Figure 9.

Table 1. Main characteristics of the samples used in the preliminary experiments.

\begin{tabular}{|l|c|c|c|c|}
\hline Material & \multirow{2}{*}{$\begin{array}{c}\text { Initial } \\
\text { charging } \\
\text { voltage } \\
\text { kV }\end{array}$} & \multicolumn{2}{|c|}{$\begin{array}{c}\text { Imploding } \\
\text { radius } \\
\text { mm }\end{array}$} & \multirow{2}{\text{Imploding}}{$\begin{array}{c}\text { percentage } \\
\text { \% }\end{array}$} \\
\cline { 3 - 4 } & before & after & \\
\hline Magnesium & 19.08 & 40 & 35.7 & 89.3 \\
\hline Magnesium & 20 & 40 & 35 & 87.5 \\
\hline $\begin{array}{l}\text { Stainless } \\
\text { steel }\end{array}$ & 20 & 100 & 92 & 92.0 \\
\hline $\begin{array}{l}\text { Stainless } \\
\text { steel }\end{array}$ & 24 & 38 & 28 & 73.7 \\
\hline $\begin{array}{l}\text { Stainless } \\
\text { steel }\end{array}$ & 25 & 38 & 27 & 71.0 \\
\hline
\end{tabular}

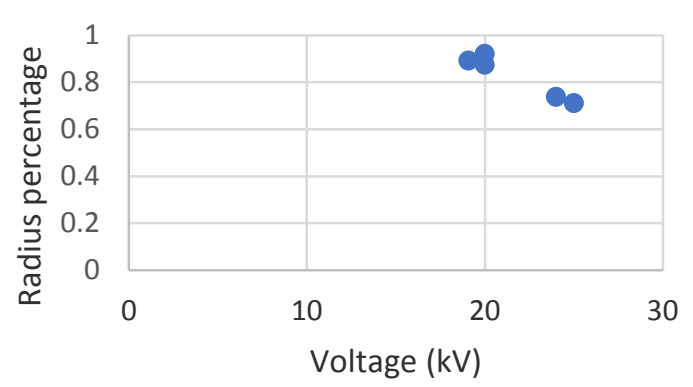

Figure 8. Voltage vs. Radius percentage.

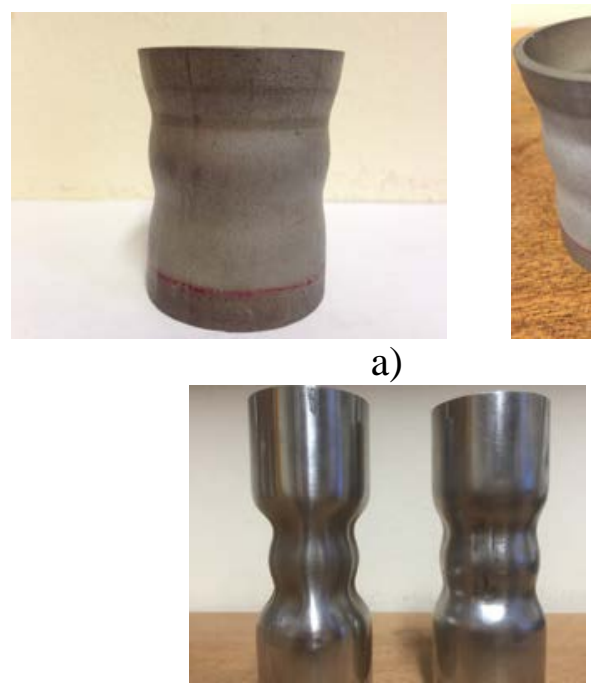

b) 


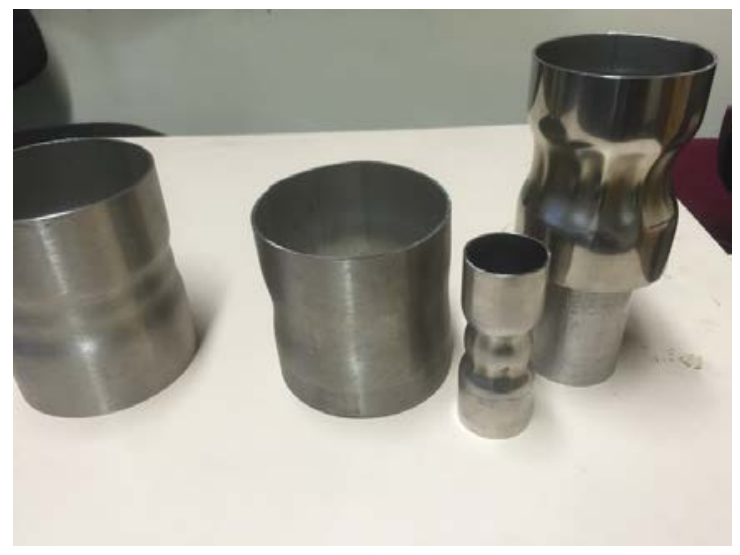

c)

Figure 9. Magneto-forming of:

a) magnesium samples; b) and c) stainless steel cylinders up to about $100 \mathrm{~mm}$ in diameter.

\section{B. Welding of stainless steel cylinders}

Figures 10 and 11 show results from an implosion where two stainless steel cylinders have been successfully cold welded. A circularity test was performed to obtain the shape of the welded section on the joined sample using a Nikon Metrology Coordinate Measuring Machine. The Renishaw SP25 scanning probe was used to take a scan around the periphery of the welded section; the corresponding software applied a Least Squares Circle (LSC) fit to the data. The plot in the Fig 12 shows the shape of the section and returns a circularity value of $48 \mu \mathrm{m}$ from the LSC fitted data. Results of the hardness of the steel samples using the nano-indentation test are also presented in Figure 13.

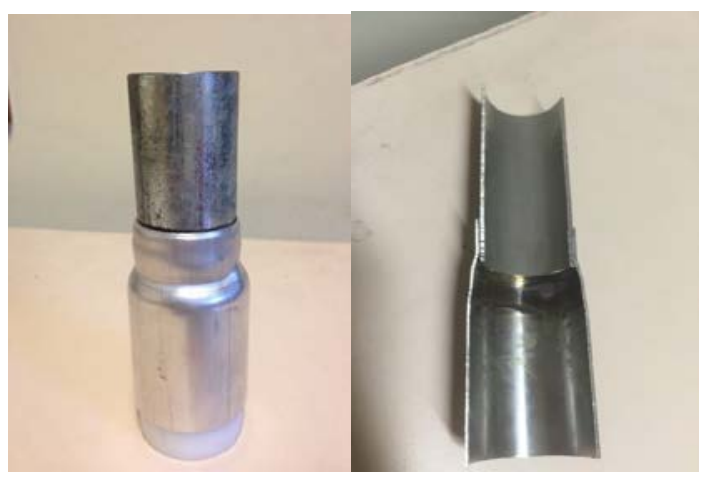

Figure 10 Typical cold welding of stainless steel cylinders.

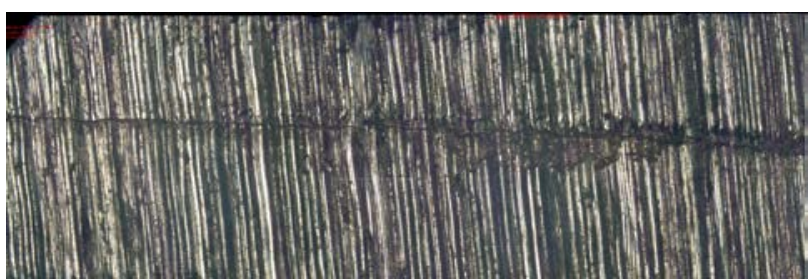

Figure 11 Photo of the cold welding interface, obtained using scanning electron microscopy.

\section{CONCLUSIONS}

Preliminary results of a magneto-forming programme are encouraging. Stainless steel and magnesium cylinders were easily magneto-formed and a first attempt of cold welding two stainless steel cylinders was successful.

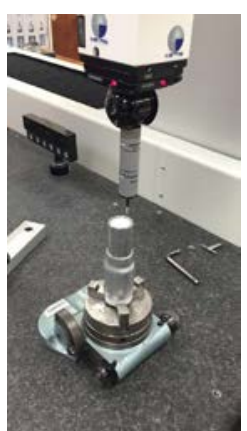

Figure 12 Testing the circularity of stainless steel samples.

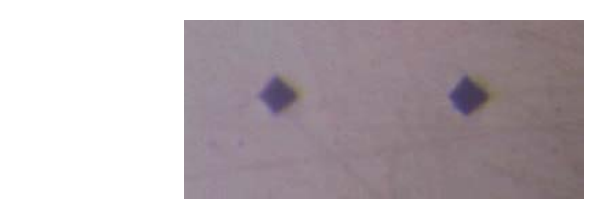

a)

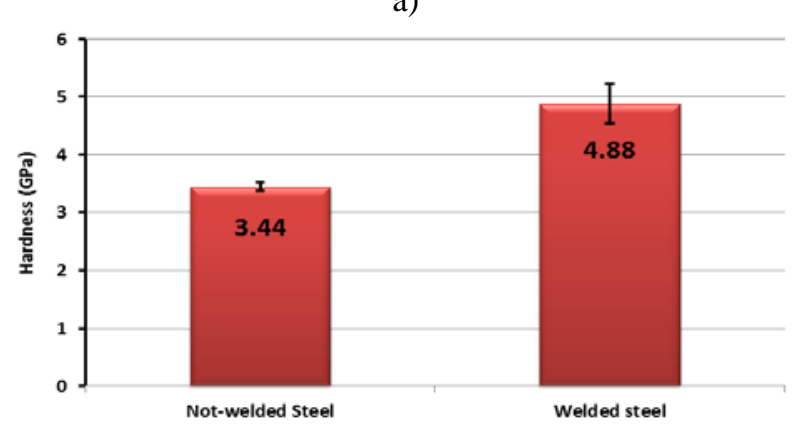

b)

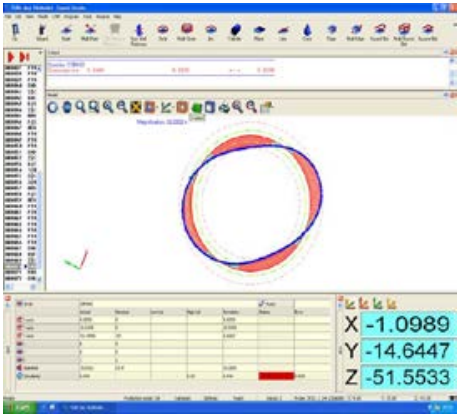

Figure 13 Results from nano- indentation study.

\section{REFERENCES}

[1] Davies, Richard W., S. Golovashchenko, and J. A. Carpenter. "Electromagnetic Forming of Aluminum Sheet." Automotive Lightweighting Materials Fiscal Year (2004): 31-38.

[2] Fowler, Clarence M., R. S. Caird, and D. J. Erickson, eds. Megagauss technology and pulsed power applications. Plenum Publishing Corporation, 1987.

[3] DeLyser, Ronald R. "Using Mathcad in electromagnetics education." Education, IEEE Transactions on 39.2 (1996): 198-210.

[4] Berger, Harold, and Leonard Mordfin, eds. Nondestructive Testing Standards--present and Future. Vol. 1151. Astm International, 1992 